\title{
O compromisso feminista com a luta decolonial antirracista
}

\section{Feminist commitment to a decolonial anti-racist struggle}

Dra. Susana de Castro susanadec@gmail.com

Professora Associada do Departamento de Filosofia Universidade Federal do Rio de Janeiro [UFRJ]

Partindo da ideia de que o feminismo é um movimento político comprometido com a justiça social em geral, o texto mostra porque o feminismo brasileiro está associado à luta antirracista. Analisa a presença da diferença colonial como origem do privilégio que pessoas brancas possuem na sociedade brasileira e da permanência do racismo cotidiano, institucional e individual. Mostra as bases coloniais do racismo estrutural e sua conexão com o projeto capitalistapatriarcal-heteronormativo de controle e assujeitamento da população nas sociedades liberais.

PALAVRAS-ChAVE Racismo. Feminismo. Genocídio. Comunidade

Departing from the idea that feminism is a political movement committed to social justice in general, the article shows why Brazilian feminism is associated with anti-racism struggle. It analyzes the presence of colonial difference as a cause of privileges white people have in Brazilian society and also of the maintenance of daily institutional and individual racism. Shows the colonial base of structural racism and its connection with capitalism's heteronormativ patriarchal project of control and submission of people in liberal societies.

KEYWORDS Racism. Feminism. Genocide. Community 
O feminismo pode ser reformista ou revolucionário. No primeiro caso, as feministas focam na busca pela igualdade de gênero, ou seja, lutam pela reforma do sistema vigente de modo a que possam receber tratamento igual aos homens por esse mesmo sistema. No segundo caso, não se trata mais de reformar o sistema, mas sim de transformá-lo e acabar com o patriarcado. As reformistas não perceberam que para os homens brancos era mais vantajoso levar em consideração os direitos das mulheres, conquanto a garantia desses direitos não ameaçasse a manutenção da supremacia branca. (bell hooks, 2019, p. 21).

Hoje, no Brasil, o feminismo está em moda. Nas lojas de departamento é comum encontrarmos camisetas com dizeres feministas do tipo 'lute como uma garota', 'girl power'. Revistas de moda e programas de TV também enaltecem o feminismo. Essas incorporações do feminismo à indústria e ao comércio nada mais são, entretanto, do que tentativas de enaltecer seus aspectos reformistas e silenciar seus aspectos revolucionários. No meu entendimento, dada a história, a política e a economia do Brasil, o feminismo só pode ser revolucionário, ou melhor não existir. Não podemos combater o sexismo e a misoginia se não estivermos dispostas a combater o sistema econômico que sustenta tanto o machismo quanto o racismo e a pobreza.

Como mostra Silvia Federici $(2017,2019)$, existe uma relação intrínseca entre capitalismo, patriarcalismo e racismo. Para Federici, a perseguição às mulheres na Europa durante os séculos XVI e XVII, conhecida como 'a caça às bruxas', assim como a colonização das terras ultramarinas e a escravidão dos não europeus foram fundamentais para a consolidação do capitalismo mundial, e, ao mesmo tempo, uma resposta das elites econômicas e políticas às revoltas camponesas na Europa que ameaçavam seu domínio. Esse é o momento da acumulação primitiva de capital. Federici (2017) mostra como a transição do feudalismo para o capitalismo foi marcada pelo cercamento das terras e a consequente expulsão dos camponeses. Apesar de viverem em situação de servidão sob o feudalismo e terem que trabalhar para a subsistência do dono das terras e sua família, os camponeses também podiam cultivar uma parte da terra para seu próprio sustento. Além da agricultura de subsistência, praticavam a agricultura comunal e o compartilhamento dos bosques e pastos. Apesar de não terem uma igualdade completa em termos jurídicos, não havia entre homens e mulheres uma divisão de tarefas por sexo, todos trabalhavam igualmente na produção. Com o cercamento das terras, as mulheres mais independentes, líderes locais, e viúvas que guardavam a memória de uma experiência comunal de agricultura foram perseguidas pela inquisição sob o falso pretexto de que haviam sido cooptadas pelo demônio. Na verdade, como mostra Federici, o objetivo era estabelecer um novo 
marco nas relações familiares de tal forma que as mulheres passassem a seguir um modelo de feminilidade dócil e obediente. Essa foi uma grande manipulação ideológica perpetrada pela igreja em conluio com os grandes proprietários e os grandes comerciantes. Era necessário impor pelo medo um modelo não subversivo de mulher, para que as mulheres voltassem a se dedicar apenas à reprodução e ao cuidado, e sem remuneração. Até então elas detinham independência econômica, pois tanto trabalhavam na agricultura de subsistência, quanto comerciavam seus poucos produtos excedentes. Com a caça às bruxas e o cercamento das terras, as mulheres europeias foram submetidas a um padrão patriarcal de feminilidade, no qual suas tarefas não eram supostamente de produção, mas apenas de reprodução. $\mathrm{O}$ que Federici mostra, entretanto, é que mesmo reduzida às tarefas domésticas não remuneradas, as mulheres também participavam da produção, na produção da mão de obra, pois era graças ao seu trabalho doméstico, de cuidado da família, que a mão de obra masculina assalariada podia subsistir, e tudo isso sem trazer ônus nenhum para o capitalista. Dessa forma o capitalista emergente, em processo de acumulação primitiva de capital, 'lucrava' duplamente, com a expropriação da mão de obra do trabalhador assalariado e com a expropriação da mão de obra não remunerada da esposa desse trabalhador.

Esse cercamento das terras é estendido para os territórios ultramarinos ocupados. Nas colônia ultramarinas, porém, a ocupação da terra é feita de modo violento, com o genocídio de parte de sua população nativa, e a escravidão de outra parte.

Como mostra Maria Lugones (2008), as comunidades dos povos indígenas viviam não só sob outra égide econômica, não acumulativa e distributivista, quanto também sobre outro modelo de distribuição de tarefas entre os sexos. O sexo biológico não era determinante para as funções sociais. Não havia a divisão de gênero a partir da divisão sexual, na qual as mulheres essencializadas como mães e os homens como trabalhadores só podiam executar tarefas próprias a essas 'identidades' sexuais. O colonizador introduziu o gênero e a divisão sexual das tarefas também como uma forma de dominação e controle, ao lado da estratégia de dominação através da ideia de superioridade racial, isto é, da ideia da superioridade da raça europeia sobre as raças não europeias.

Para corroborar a sua hipótese, Lugones cita as pesquisas de Paula Gunn Allen e Oyéronké Oyewùmi. A primeira mostra como muitas tribos de nativos norte americanos eram ginecocratas, isto é, nelas a força primária do universo era feminina. A transformação dessas tribos igualitárias e ginecocratas em hierárquicas e patriarcais se deu graças à intervenção do cristianismo e a subs- 
tituição da força primária feminina por uma masculina. Para Oyewùmi, dois processos foram cruciais na colonização das tribos Yorubás, a inferiorização das mulheres e a imposição da ideia de raça, e a consequente inferiorização dos africanos. Antes da colonização, as mulheres ocupavam posições de líderes, possuíam propriedade sobre suas terras (LUGONES, 2008, p.88-89). Gênero passa a ser uma forma de dominação pelos colonizadores na medida em que obriga os nativos a se submeterem a uma nova forma de organização social, separada de seus hábitos e costumes. Ordem essa na qual a mulher necessariamente estaria submetida ao homem, e na qual o sexo biológico determinava desde o nascimento a função social do indivíduo dentro da sociedade.

No Brasil, à época do descobrimento, segundo relato dos primeiros colonizadores, havia o costume entre as populações indígenas de cada qual escolher o papel social que quisessem independente do sexo biológico com o qual tivessem nascido (NAVARRO-SWAIN, 2004, p. 20).

Os índios do Brasil conheciam poucas restrições sexuais, à parte algumas interdições entre parentes. Por outro lado, fato notável para os estudos de gênero, as categorias mulher/ homem não eram definidas a partir do sexo biológico. Com efeito, cada qual podia escolher sua ligação a um ou a outro grupo e exercer sua sexualidade como bem entendia. A homossexualidade era uma prática como qualquer outra e não levava a nenhuma espécie de exclusão (NAVARRO-SWAIN, 1996).

O projeto colonial moderno cristão-capitalista introduziu como forma de dominação o modelo de racionalidade categorial segundo o qual o mundo é estruturado de forma dicotômica e hierárquica, de tal modo que homem e mulher são seres completamente diferentes (apesar de, do ponto de vista fisiológico, a única grande diferença são os órgãos sexuais e os hormônios, sendo todo o restante do corpo idêntico um do outro) e o homem é superior à mulher, o cristão superior ao pagão, o branco ao não branco, e o heterossexual ao homossexual. O patriarcado europeu trouxe consigo a moral cristã e o controle da sexualidade. Não se admitia nenhuma forma de comportamento sexual que saísse dos limites impostos pelo comportamento heterossexual, uma vez que a expressão da sexualidade do ponto de vista do patriarcado deve estar primordialmente relacionada aos interesses econômicos do colonizador. A heterossexualidade compulsória e a 'naturalização' dos papéis sociais (a ocultação do fato de que 
não são 'naturais', mas sim culturalmente determinados), tornam relações assimétricas e hierárquicas, tais como as que se estabelecem entre homem e mulher, o modelo correto de relação conjugal, porque 'natural'.

Não podemos entender plenamente a realidade social brasileira contemporânea, marcada pela violência contra as mulheres, os negros e os povos indígenas, se não tivermos em mente o processo capitalista de colonização europeia das nossas terras. Assim como Federici conclui que a ideia de suposto progresso com o surgimento do capitalismo ${ }^{1}$ é uma farsa, pois a transição do feudalismo para o capitalismo representou a perda de liberdades para as mulheres e para os trabalhadores, também podemos dizer que a ideia de que o europeu trouxe civilização e progresso para as Américas é uma farsa, pois a realidade é que, desde então, se promoveu a perda do sentido do comum, a dilapidação das riquezas naturais, o extrativismo desordenado e a violência contra os que ousam rejeitar o modelo econômico de mercado livre.

\section{Brasil hoje}

Em depoimento dado a uma revista nacional sobre sua visita ao Brasil, a escritora e feminista Chimamanda Ngozi Adichie relatou que foi a um restaurante sofisticado com o seu marido e ficou impressionada em constatar que não havia uma pessoa negra no local. Dessa experiência ela conclui que a história que as pessoas no Brasil contam de que não há racismo no Brasil é falsa, visto que os negros claramente são invisíveis e não possuem acesso ao poder. ${ }^{2}$

Quando falamos sobre o racismo tendemos normalmente a associá-lo automaticamente ao racismo individual, ou seja, aquelas situações nas quais pessoas negras são flagrantemente insultadas por outras por causa da sua cor de pele, mas, além do racismo individual, cotidiano, existe o racismo estrutural e o institucional. É, principalmente, por causa desses últimos que quando inquirida, qualquer brasileiro/a tende a dizer que não é racista, mas o que essa resposta não mesura são as imagens preconceituosas sobre as pessoas negras que subjazem às suas crenças, até mesmo quando o entrevistado é uma pessoa negra,

1 Do ponto de vista histórico, sabemos que o feudalismo deu lugar às monarquias absolutas, porém também sabemos que tais monarquias serviam aos interesses mercantis da burguesia ascendente, na medida em que o Estado Nacional, centralizado, permitia uma melhor segurança nas trocas mercantis, o apoio estatal na ampliação do mercado, e a monetarização da economia, etapas fundamentais para a acumulação primitiva do capital no capitalismo.

2 Marie Claire, no. 337, abril de 2019. 
associando-as aos estereótipos negativos como 'preguiçosa', 'má', 'agressiva'. O racismo estrutural é a normalização e legitimação da supremacia branca graças à conjunção de diversas forças comprometidas em perpetuar a desigualdade racial, tais como a narrativa eurocêntrica da história nacional, o currículo educacional eurocentrado, políticas capitalistas, meritocráticas, de governo e de economia. O racismo institucional é a prática generalizada das instituições de favorecer pessoas brancas e prejudicar pessoas não brancas (DAVIS, 2019, p. 32-33; CASTRO, 2020, p. 150). Um exemplo bem evidente do racismo institucional é a abordagem policial na cidade do Rio de Janeiro, na qual a pessoa negra é sempre suspeita, e também a ação policial mortífera nos morros cariocas. O policial carioca não entra em um bairro da zona sul atirando como ele faz nos morros. Ele só entra atirando e matando nos morros porque sabe que sua prática é legitimada pela sociedade e ele não será punido por causa do dispositivo jurídico racista do 'excludente de ilicitude'.

O Brasil nasceu com o sangue do genocídio dos povos originários e a escravidão dos povos africanos e nativos. Desse fato deriva a pedra fundamental do racismo. Povos originários e africanos foram mortos ou escravizados porque o europeu thes conferiu inferioridade racial, ainda que o termo 'raça' não possua base genética ou biológica. "Pessoas" brancas e "pessoas" negras é uma invenção histórica, sem base científica. Além disso, essa divisão inexistia antes das invasões europeias nos territórios do sul do Atlântico. Essa situação traumática não foi até hoje abordada coletivamente, de tal modo que atua como um trauma reprimido, legitimando a narrativa hipócrita da 'democracia racial'. Precisamos, entretanto, curar esse trauma para que possamos ter uma sociedade verdadeiramente democrática, na qual as pessoas tenham de fato oportunidades iguais, independente da sua classe social, cor de pele ou gênero. A única forma de cura possível para um trauma, já assinalava, o pai da psicanálise, é a fala. Precisamos falar sobre os crimes perpetrados no passado, para que possamos confrontar as práticas racistas do presente.

\section{A ferida colonial}

Em seu livro Memórias da Plantação, Grada Kilomba mostra de que forma a ferida colonial é aberta a cada vez que uma pessoa negra ou de cor sofre uma agressão racista. A partir de entrevistas feitas com mulheres afro-alemãs, conclui que o pressuposto colonial irracional da superioridade das pessoas brancas legitima a maneira grosseira com a qual racistas interpelam na Alemanha as 
pessoas de cor, invadindo sua privacidade ou mesmo tocando seu corpo e cabelo. Elas se recusam a aceitar que essa pessoa de cor é alemã como elas, como se fosse uma verdade trivial que a pele branca seria condição para a nacionalidade alemã. Somente na medida em que foram adquirindo consciência de que as suas experiências com o racismo não podiam ser banalizadas como 'normais', as entrevistadas foram capazes de sair de padrões violentos de relacionamentos a que se submetiam cada vez que se relacionavam com pessoas brancas, namorados, alunas, colegas de trabalho. Fica claro nos relatos, que o racismo estrutural presente na sociedade alemã afetava igualmente a todos os brancos privilegiados, independente do sexo. Homens e mulheres reproduzem comportamentos violentos quando se trata de manter seus privilégios raciais.

Os traumas do genocídio e da escravidão são reencenados perpetuamente através das gerações quando não se os confronta. A ferida racial colonial que serviu para separar hierarquicamente colonizador e colonizado é uma chaga que impede a nação brasileira de se unificar em torno de um projeto mais humano de democracia. Assim como quando incautos defendem a ditadura militar e seus métodos autoritários nos vemos obrigados a nos empenhar em não deixar esmorecer a memória dos que tombaram defendendo as liberdades democráticas, a soberania nacional e a justiça social, também nos compete enquanto feministas comprometidas com a luta antirracista tanto denunciar os crimes do projeto europeu de colonização da América Latina, quanto estimular a que tenhamos mais espaços de diálogo nos quais possamos narrar nossas experiências sem procurar atender a expectativa da norma eurocêntrica racista.

Grada Kilomba faz referência à imagem da escravizada brasileira Anastácia com a mordaça para ilustrar o quanto a dominação racial passa pela negação do lugar de sujeito e de fala. A mesma mordaça usada para calar a boca das mulheres no Brasil colonial, era usada na inquisição para calar a boca e torturar as mulheres acusadas de bruxaria na Europa, como narra Silvia Federici (2019). Em ambos os casos o objetivo é o mesmo, impedir que as verdades universais do capitalismo patriarcal heterocentrado e racista sejam postas em dúvida.

\section{O neocolonialismo contemporâneo}

Diante da crise mundial do capitalismo, assistimos abismados a reencenação de procedimentos explicitamente neocoloniais sob a égide do suposto racionalismo econômico do capitalismo neoliberal. É bastante óbvio que a receita de sucesso econômico prometida pela adoção de medidas austeras de 
contenção de gastos com saúde e educação, e contenção de despesas com folha de pessoal, o chamado enxugamento do Estado, serve exclusivamente aos interesses da classe dos empresários nacionais e internacionais. Forja-se a narrativa de que seremos competitivos e ricos quando acabarmos com as leis de proteção aos trabalhadores.

Quando o presidente da Nação diz que que os ambientalistas precisam ser confinados na selva amazônica para que o Estado possa permitir mineração em terras indígenas, ${ }^{3}$ fica claro que estamos revivendo um avanço de um capitalismo predatório que não aceita a possibilidade de existência de um território com riquezas naturais que não seja explorado economicamente. Essa fala significa quase uma autorização oficial à perseguição aos líderes indígenas brasileiros. Além disso, assistimos boquiabertos a naturalidade com a qual o mandatário da República brasileira emite opiniões misóginas sobre profissionais da imprensa para regozijo da claque que o escuta. A associação entre misoginia, racismo e capital do atual governo ilustra de maneira clara quais são os pilares do (neo-) colonialismo. Os três andam de mãos dadas e trazem como 'abre alas' as religiões evangélicas. Como disse o antropólogo Eduardo Viveiros de Castro em recente entrevista: "Há uma ofensiva econômica e religiosa contra os povos indígenas. $\mathrm{O}$ grande capital quer as terras, e os evangélicos querem as almas. ${ }^{4}$

Ao mesmo tempo em que se faz mais do que urgente desmascarar a violência do processo civilizatório europeu, também se faz necessário resgatar formas de convivência comunitárias ancestrais, pré-conquista, mais harmônicas, menos competitiva. Seguindo Fania Davis (2019), acredito que antes do processo de colonização existia em todas as partes do mundo formas de convivência na qual o valor do indivíduo era medido pela sua relação com a comunidade e não separado dela. Ainda hoje comunidades nativas de povos das florestas e africanos mantêm esse ethos da unidade comunitária. Se um membro da comunidade comete uma falta, a reparação deve ser feita em comum acordo com a comunidade e pela vítima. Em seus relatos, as afro-alemãs entrevistadas por Grada Kilomba contam como estranhavam quando pessoas negras totalmente desconhecidas as cumprimentavam na rua. Só mais tarde, depois de já terem feito o processo de confronto do trauma reprimido e o resgate da negritude, é que foram entender que esse cumprimento tinha a finalidade de mostrar a união entre os membros da grande família dispersa dos negros descendentes dos transportados do continente Africano para as colônias.

3 Jornal O Globo de 6 de fevereiro de 2020.

4 Jornal O Globo, 16 de fevereiro de 2020. 


\section{Conclusão}

A noção de sororidade foi bastante criticada por setores do feminismo negro por representar uma falsa união entre as mulheres, já que as condições de classe e raça acabavam trazendo relações hierárquicas intransponíveis. bell hooks, entretanto, discorda dessa crítica. Para ela, o slogan "a sororidade é poderosa" ainda faz sentido na medida em que mulheres individuais estão dispostas a abrir mão de seu poder de dominação e exploração de grupos subordinados de mulheres $(2019$, p. 36). O fato de pessoas brancas serem favorecidas pelo racismo institucional faz com que tenham a obrigação moral de combater o racismo estrutural (a crença não refletida não supremacia branca). Nesse sentido, levando em consideração o racismo do status quo, não é possível pensar em um feminismo hoje que não esteja fortemente comprometido com a luta antirracista. Sem que abracemos o compromisso de abrir mão de privilégios herdados de uma tradição colonial racista, não conseguiremos transformar o sistema patriarcal brasileiro calcado no racismo eurocêntrico.

CASTRO, Susana de. "Condescendência: estratégia pater-colonial de poder". In: Hollanda, Heloisa Buarque. Pensamento feminista hoje: perspectivas decoloniais. Rio de Janeiro: Bazar do tempo, 2020. P. 140-152.

DAVIS, Fania. Race and Restorative Justice. Nova Iorque: Good Books, 2019.

FEDERICI, Silvia. O calibã e a bruxa. Trad. Coletivo Sycorax. São Paulo: Elefante, 2017.

Mulheres e a caça às bruxas. Trad. Heci Regina Candiani. São Paulo: Boitempo, 2019.

Hooks, Bell. O feminismo é para todo mundo. Trad. Bhuvi Libânio. Rio de Janeiro: Rosa dos Ventos, 2019.

KILOMBA, Grada. Memórias da Plantação - episódios de racismo cotidiano. Trad. Jess Oliveira. Rio de
Janeiro: Cobogó, 2019.

LUGONES, Maria. “Colonialidad y Género”. In: Tabula Rasa. Bogotá: No. 9, julho-dezembro, 2018. P. 73-101.

NAVARRO-SWAIN, Tania. O que é o lesbianismo. São Paulo: Brasiliense, 2004.

“A construção imaginária da história e dos gêneros: o Brasil no século XVI”. In: Textos de História. Brasília: UnB, vol. 4. N.2., 1996.

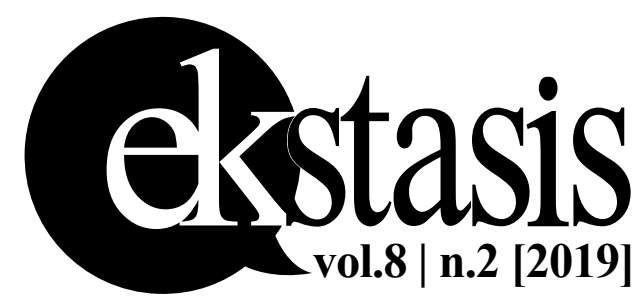

